\title{
Should didactic methods be subject of institutional policy? Reflections of a retired teacher
}

\author{
Jochanan Benbassat* \\ Department of Health Policy Research, Myers-JDC-Brookdale Institute, Jerusalem, Israel
}

\begin{abstract}
Background: Medical schools are replacing the traditional "teacher-centered" instruction that casts students as passive recipients of lectures by "learner-centered" methods that entail student involvement. Some schools have adopted learner-centered methods as institutional policy.

Objective: To describe the author's teaching approaches at two Israeli medical schools in the 1970s - 1990s, and explore the pros and cons of a policy that requires from faculty to use a single teaching method.

Observations: Students were interested in lectures that summarized clinical knowledge and in experiences aimed at imparting clinical skills. However, students appeared to be bored by lectures that they perceived as clinically irrelevant, or as preaching values. In such domains challenging small groups of students to cope with a specific task was more effective in achieving the learning objective.

Implications: Different topics may require different teaching methods. The author proposes to familiarize faculty with the strengths and weaknesses of lectures, flipped classrooms, problem- and inquiry-based learning; develop guidelines for assessing the effectiveness of these teaching methods; and encourage faculty to choose the method with which they feel comfortable, and which they consider optimal for the subject to be taught.
\end{abstract}

\section{Introduction}

Since the 1970s, medical schools have been replacing the traditional "teacher-centered" instruction that casts students as passive recipients of lectures, by "learner-centered" methods that encourage student involvement. Examples of learner-centered methods are the "flipped classrooms" that assign subject matter as homework and devote class time to discussions [1], and "problem-based" learning that challenges small groups of students to cope with a task. Some medical schools have adopted problem-based learning as institutional policy. A strict problem-based approach assigns the responsibility of learning to the students and expects the tutor only to facilitate the discussions; "inquiry-based" learning expects the tutor to be a subject matter specialist and provide students with information and guidance in addition to facilitation of discussions [2].

My undergraduate medical education in the 1950s was mostly through lectures, and during my practice in academic hospitals between 1960 and 1995, I tended to teach as I was taught. I perceived no difficulties in imparting skills, such as the physical examination, or knowledge by lecturing on clinical topics. However, students appeared impatient when lectured on domains that they perceived clinically irrelevant or "preaching" professional values. In such domains, "inquiry-based" learning, i.e., helping small groups of students to cope with a specific task appeared to arouse their interest more than lectures, flipped classrooms and even one-on-one explanations.

In this paper, I provide examples of topics that appeared to me better suited for inquiry-based learning. I explore the advantages and weaknesses of requiring faculty to adopt a single teaching approach and propose granting freedom to faculty to choose the teaching method that they feel most comfortable with and most suited for the topic to be taught.

\section{Topics that appeared to be better suited for inquiry- based learning than for lectures}

My colleagues and I have already reported in detail our approach to inquiry-based learning of patient interviewing, meeting patient expectations, patient discrimination by doctors and the patient's personal history [3-6]. Briefly, in response to students' feelings that lectures on patient interviewing were sermons in essential courtesy, we challenged them to state the causes of patient dissatisfaction with doctors (e.g., "the doctor was impolite", "the doctor did not listen", "the doctor did not understand") and to suggest ways to reduce them [3]. In response to students' feelings that meeting patient expectations was a non-problem, we challenged them to state the possible expectations of a hypothetical patient with sore throat, cough and runny nose of two days' duration (receive a doctor's note for a two-day sick leave; a thorough examination with a view of treatment; or a referral to a specialist in order to enquire if her illness was hay fever). Students agreed that elucidating these expectations was important and that the doctor could accomplish this by asking patients who do not make their expectations clear: "Before I advise you, it is important for me to know what specifically makes you worry?" [4].

*Correspondence to: Jochanan Benbassat, Department of Health Policy Research, Myers-JDC-Brookdale Institute, P.O.Box 13087, Jerusalem 91130, Israel, E-mail: benbasat@jdc.org.il

Key words: medical education, teacher-centered and learner-centered educational approaches, inquiry based learning, doctor-patient relations

Received: December 15, 2019; Accepted: December 23, 2019; Published: December 26, 2019 
In response to students' being offended by lectures on patient discrimination by doctors, I initiated after some teaching rounds discussions of patient counseling by asking a student to assume the role of the doctor while I assumed the role of a patient whom we had seen during rounds. While pretending to have the patient's disease, I retained my identity and medical background, thereby creating a situation in which the student could provide counseling without any barriers in communication. As the simulation proceeded, students realized that the real patient was not similarly informed thereby opening the door to discussions of the discrepancies between the counseling that was afforded to me and that offered to patients.

A commonly stated reason for the discrepancies was "The patient never asked questions." I pointed out that physicians usually underestimate patients' needs for information [7], and that all patients would ask questions if they are given an appropriate opportunity. Another reason was "It is impossible to communicate with the patient because ... "In response, I asked the students to overcome various barriers to communication. Even without any prior knowledge, students suggested sensible ways to do that, e.g., by using interpreters in cases of lingual mismatch, non-medical terms with lay people, or slower speech, lip reading and reducing the distance from patients with hearing impairment [5].

In response to students' doubts of the value of the patient's personal history, I asked them to outline a doctor's encounter with a hypothetical healthy person who "just wants to introduce himself". Students suggested that, in the absence of any complaints to address, the doctor would discuss health promotion and disease prevention. They identified the two types of information needed for this purpose: risk indicators that would increase susceptibility to disease, and resources, which may help a patient cope with it. Students readily identified risk indicators, such as age and family history. I informed them about the association between morbidity and life events $[8,9]$, and between mortality and socioeconomic status $[10,11]$. I agreed that the distinction between risk indicators and resistance resources is vague, as the absence of a resistance resource, such as immunity, may also be considered a risk indicator. However, the term "resistance resources" is useful to refer to health insurance and social support systems (e.g., family and friends) that have been shown to be health promoting [12].

Students argued that this information is not clinically useful, as doctors cannot combat loneliness and poverty. I responded that neither can doctors alter heredity and age. Still, such information provides an insight into patients' vulnerability. The higher morbidity of disadvantaged persons suggests that any symptom in a poor, elderly, or uneducated person, or in one who has experienced a significant life event may herald a more serious disease than in patients without these indicators, just as the probability of a life-threatening infection in a neutropenic patient, who develops fever while on chemotherapy, is higher than that in an otherwise healthy person with the same degree of fever. Therefore, rather than discriminating against older, poorer, less educated and emotionally instable patients, doctors should single such patients as being more vulnerable [6].

\section{Discussion}

Since its introduction at McMaster in 1969, problem-based learning has been used in medical schools throughout the world. It makes sense that it achieves important objectives, such as making decisions in unfamiliar situations, appreciating other persons' point of view, collaborating in teams, and identifying one's own strengths and weaknesses. Graduates of problem-based programs have been reported to equal in knowledge those of traditional medical schools [13], and it has been claimed that the inquiry-based approach is even superior to problem-based learning [14].

Indeed, inquiry-based learning of the topics that I mentioned earlier encouraged students to build on their previous understanding, generate their own knowledge, express their beliefs and uncertainties and reconsider their views in an atmosphere of critical reflection and respect for the views of others. Still, I am uncertain whether teachers should be required to apply a single state-of-the-art method for all medical subjects to be learnt. On the one hand, educators agree that a central control of the content and methods of delivery of the educational program is fundamental for the success of today's medical education. Such a control would attempt to overcome faculty's lack of expertise in education and tendency to teach as they were taught. Furthermore, sometimes a talented teacher with a commanding presence may erroneously decide that lectures work, contrary to undisputed evidence that they do not. On the other hand, requiring from staff at all levels to adopt a single didactic approach limits their freedom to use the one that they feel most comfortable with, or consider optimal for specific topics.

For example, some teachers may disagree with the view that learning is the responsibility of learners (as in strict problem-based learning), and feel that faculty should assume responsibility for students' professional development by appropriate guidance. The undisputed limitations of lectures indeed justify the promotion of flipped classrooms; yet, both learners and faculty would certainly benefit from opportunities to communicate a thesis in the form of a lecture, as practiced in scientific meetings. Finally, one of the justifications of learner-centered approaches was to promote students' self-directed learning. In the 1960 s - 1990s, self-directed learning required guidance and investment of time and effort; today, the easy access to data stores has transformed self-directed learning into a common skill.

Therefore, I believe that the time has come to review the didactic approaches in medical schools in order to recommend a policy that promotes the development of both students and teachers. I propose that, rather than requiring from staff at all levels to adopt a specific didactic approach, teachers should be offered opportunities to become familiar with alternative teaching methods, such as live or videotaped lectures, flipped classrooms, problem-based learning and inquiry-based learning. Teachers should be encouraged to assess the effectiveness of different teaching methods for differing topics, and they should be permitted to choose the methods with which they feel most comfortable and consider optimal for arousing students' interest in the specific domain being taught.

\section{Notes on the author}

Jochanan Benbassat was a staff physician at the department of Medicine of the Hadassah University Hospital in Jerusalem between 1962 and 1992, and since 1983, he was Professor of Medicine and chair of Medical Education at the Hebrew University in Jerusalem. In 19921997, he headed the department of Sociology of Health and chair of Behavioral Sciences in Medicine at the Faculty of Health Sciences in Beer-Sheva. Since 1998, he is a research associate at the Health Policy Research Program of the JDC Meyers-Brookdale Institute.

\section{References}

1. Chen F, Lui AM, Martinelly SM (2017) A systematic review of the effectiveness of flipped classrooms in medical education. Med Educ 51: 585-597. [Crossref]

2. Savery JR (2006) Overview of Problem-based Learning: Definitions and Distinctions The Interdisciplinary Journal of Problem-based Learning 1: 9-20. 
3. Benbassat J, Baumal R (2001) Teaching doctor patient interviewing skills using an integrated learner and teacher-centered approach. Am J Med Sci 322: 349-357.

4. Benbassat J (2015) Doctor-Patient Relations. In Teaching professional attitudes and basic clinical skills to medical students. A practical guide. Springer International Publishing Switzerland.

5. Benbassat J, Baumal R (2002) A step-wise role-playing approach for teaching patient counseling skills to medical students. Patient Educ Couns 46: 147-52. [Crossref]

6. Benbassat J (2015) Recording a patient's personal / psychosocial history and examination of asymptomatic persons. In Teaching professional attitudes and basic clinical skills to medical students. a practical guide. Springer International Publishing Switzerland.

7. Mira JJ, Guilabert M, Perez-Jover V, Lorenzo S (2014) Barriers for an effective communication around clinical decision making: an analysis of the gaps between doctors' and patients' point of view. Health Expect 17: 826-839.

8. Holmes TH, Rahe RH (1967) The social readjustment rating scale. J Psychosom Res 11: $213-228$.
9. Elliot AJ, Turiano NA, Infurna FJ, Lachman ME, Chapman BP (2018) Lifetime trauma, perceived control, and all-cause mortality: Results from the Midlife in the United States Study. Health Psychol 37: 262-270.

10. Antonovsky A (1967) Social Class, Life Expectancy, and Overall Mortality. Milbank Mem Fund Q 45: 31-73. [Crossref]

11. Rauch B (2018) Socioeconomic status: A powerful but still neglected modulator of cardiovascular risk. Eur J Prev Cardiol 25: 981-984.

12. Hawkley LC, Cacioppo JT (2010) Loneliness Matters: A Theoretical and Empirical Review of Consequences and Mechanisms. Ann Behav Med 40: 218227. [Crossref]

13. Vernon DT, Blake RL (1993) Does problem-based learning work? A meta-analysis of evaluative research. Acad Med 68: 550-563.

14. Schmidt HG, Rotgans JI, Yew EHJ (2011) The process of problem-based learning: what works and why. Med Educ 45: 792-806. [Crossref]

Copyright: (O2019 Benbassat J. This is an open-access article distributed under the terms of the Creative Commons Attribution License, which permits unrestricted use, distribution, and reproduction in any medium, provided the original author and source are credited. 